\title{
Severe hypertension and flushing in a patient with a non-metastatic carcinoid tumour
}

\author{
Hypertension and flushing with a solitary carcinoid tumour
}

R. M. JONES AND DANA KNIGHT

\begin{abstract}
Summary
A case of multiple endocrine adenopathy type I associated with a solitary carcinoid tumour is described. During anaesthesia the characteristic syndrome consisting of hypertension, tachycardia and flushing occurred. The possible mechanisms for this are discussed.
\end{abstract}

\section{Key words}

Surgery; carcinoid.

It is generally agreed that the presence of hepatic metastases is necessary for the development of the typical carcinoid syndrome. ${ }^{1,2}$ Most carcinoids of the mid-gut secrete a variety of vasoactive substances but detoxication of these products usually occurs in the liver. When hepatic metastases are present, however, vasoactive substances are able to gain access to the suprahepatic circulation. This case report describes the occurrence of a typical 'malignant' carcinoid attack occurring during anaesthesia, in a patient not previously suspected of having a carcinoid tumour, but who was known to have multiple endocrine adenopathy (MEA).

\section{Case history}

A 48-year-old woman was admitted to hospital for hysterectomy for multiple uterine fibroids. In 1968 she had undergone a left nephrectomy for pyelolithiasis and three years later a parathyroid adenoma was discovered during investigation for hypercalcaemia. During her admission for subtotal parathyroidectomy the patient complained of recurrent epigastric pain and investigation of this revealed severe peptic ulceration associated with a raised serum gastrin level of $810 \mathrm{pg} / \mathrm{ml}$ (normal less than $95 \mathrm{pg} / \mathrm{ml}$ ). The diagnosis of Zollinger-Ellison syndrome was made and a total gastrectomy and distal pancreatectomy were performed. During the operation two pancreatic adenomas were removed, substantiating the diagnosis of Zollinger-Ellison syndrome. A diagnosis of MEA type I was also made at this time. The patient was subsequently asymptomatic but continued with regular surgical out patient review.

She was admitted to hospital on this occasion for hysterectomy because an enlarged uterus was displacing the right ureter, causing hydronephrosis. On admission to hospital her medication included vitamin $B_{12}$ and iron supplements. All laboratory investigations as well as the electrocardiogram and chest X-ray were normal. There

Ronald M. Jones, MB, FFARCS,* Instructor of Anesthesiology, Dana Knight, BA, Sc, CRNA, Staff Nurse Anesthetist, University of Michigan Medical Center, Department of Anesthesiology, Ann Arbor, MI 48109, USA. Correspondence should be sent to Ronald M. Jones, MB, FFARCS, Department of Anaesthetics, The City Hospital, Hucknall Road, Nottingham, England.

* Present appointment: Consultant Anaesthetist, The City and University Hospital, Nottingham. 
was no history of paroxysmal attacks of flushing or bronchospasm. On arrival in the operating room the patient was given $5 \mathrm{mg}$ of diazepam, intravenously, and after 5 minutes preoxygenation, anaesthesia was induced with thiamylal (a thioderivative of quinalbarbitone) $250 \mathrm{mg}$ and tracheal intubation facilitated with suxamethonium $80 \mathrm{mg}$. Anaesthesia was maintained with $70 \% \mathrm{~N}_{2} \mathrm{O}$ and $\mathrm{O}_{2}$ plus enflurane $1-2 \%$. Muscle relaxation was obtained with pancuronium, a total of $5 \mathrm{mg}$ being administered during the operation. Anaesthesia was supplemented with increments of intravenous fentanyl to a total of $450 \mu \mathrm{g}(9 \mu \mathrm{g} / \mathrm{kg})$. The operation proceeded uneventfully for 20 minutes but during exploration of the abdomen the arterial pressure rose suddenly from $130 / 80$ to $220 / 120 \mathrm{mmHg}$. This was associated with an increase in heart rate from 90 to 120 beats/minute. The depth of anaesthesia and degree of analgesia were thought to be sufficient for the circumstances and the suddenness of the rise in blood pressure and heart rate were difficult to explain. The possibility of the patient having a phacochromocytoma was entertained but no obvious suprarenal masses were palpable. Approximately 3 minutes after the rise in blood pressure had occurred, the face and neck were noted to be markedly flushed. The possibility of a carcinoid attack was discussed and subsequently a small tumour was felt in the appendix. Frozen sections of this tumour confirmed that it was a carcinoid tumour. The hypertension and tachycardia responded to an increase in the concentration of enflurane to $3 \%$ and to $0.5 \mathrm{mg}$ of propranolol intravenously, and by the time that the small appendicular tumour had been removed (approximately 15 minutes) the systolic blood pressure had stabilised at between 130 and 150 $\mathrm{mmHg}$. Examination of the liver revealed it to be free from obvious metastases. The patient made an uneventful recovery from anaesthesia and surgery. Estimation of urinary 5-hydroxy-indolacetic acid (5HIAA) and plasma serotonin level, before her discharge from hospital revealed these to be within normal limits.

\section{Discussion}

Multiple endocrine adenopathy (MEA), which may be familial, describes the occurrence of tumour formation or hyperplasia in two or more endocrine glands in the same subject. Two types are recognised. Type $I$ in which the parathyroid glands are most frequently involved, followed in frequency by pancreatic and anterior pituitary gland involvement. This patient is included in this category, which is not infrequently associated with carcinoid tumours. ${ }^{3}$ Type 2 (Sipple's syndrome) consists of medullary carcinoma of the thyroid associated with phaeochromocytoma and, on accasion, other lesions such as neurofibromatosis. Multiple endocrine adenomas and carcinoid tumours are examples of apudomas, tumours with a common embryological origin in neuroectoderm, which secrete amines and peptides. The amines and peptides produced by apudomas may cause a variety of haemodynamic disturbances and alterations in plasma electrolyte and glucose concentrations. Carcinoid tumours arise from the cntcrochromaffin cells of the gastrointestinal tract. They most commonly occur in the appendix $(36-46 \%)$, but less than $3 \%$ of these have distant metastases, and there are no previous case reports of solitary appendicular tumours producing the carcinoid syndrome. ${ }^{4}$ The implications for the anaesthetist of apudomas $^{3}$ and the carcinoid syndrome $e^{4}$ have been reviewed, and these will not be restated here. The increase in blood pressure and pulse rate in patients with the carcinoid syndrome is predominantly due to serotonin (5-hydroxytryptamine) release from the tumour cells, whilst the characteristic flush and bronchospasm are mainly due to bradykinin, which is formed in the blood by the action of the enzyme kallikrein, secreted by the tumour cells. In the case presented, the sudden onset of hypertension and tachycardia associated with flushing of the face and neck is characteristic of a carcinoid attack. The possibility of a carcinoid tumour had been entertained before the intestinal tumour had been discovered, mainly because of the very striking skin flushing which occurred. At laparotomy and subsequent follow up in the postoperative period, no evidence of metastases could be found and the urinary 5HIAA and serum serotonin were normal. Prior to surgery the patient had not been subject to symptoms suggestive of the carcinoid syndrome. Two explanations for the occurrence of a typical attack without hepatic metastases are possible. Firstly, during abdominal exploration, surgical manipulation of the tumour may have caused such a large release of vasoactive amines into the circulation, that the detoxifying action of liver enzymes was overcome. Secondly, liver blood flow and function during anaesthesia is known 
to be reduced ${ }^{5}$ and concentrations of serotonin and bradykinin which in normal circumstances would be destroyed, may have gained access to the supra-hepatic circulation, producing the characteristic clinical syndrome. A combination of both factors may be a likely explanation.

\section{Conclusions}

When anaesthetising a patient known to have a tumour of neuroectodermal origin, the possibility of the presence of other tumours possibly producing physiologically active hormones should be borne in mind. Secondly, during anaesthesia a patient with a solitary carcinoid tumour may exhibit all the characteristic signs of the carcinoid syndrome. The hypertension and tachycardia present in this patient was quickly controlled by means of an increased concentration of enflurane and intravenous propranolol.

\section{References}

1. Stone HH, Donnelly CC. The anesthetic significance of serotonin secreting carcinoid tumors. Anesthesiology 1960; 21: 20312.

2. DÉRY R. Theoretical and clinical considerations in anaesthesia for secreting carcinoid tumors. Canadian Anaesthetists Society Journal 1971; 18: 245-63.

3. Whitwam JG. APUD cells and apudomas. Anaesthesia 1977; 32: 879-88.

4. Mason RA, Steane PA. Carcinoid syndrome: its relevance to the anaesthetist. Anaesthesia 1976; 31: $228-42$.

5. Thorshauge C. Hepatic blood flow during anaesthesia. Acta Anaesthesiologica Scandinavica 1969; 37(suppl): 205. 